\title{
La urbanización en Ecuador y la importancia de la planificación estatal en la creación de una ciudad intermedia (2007-2017): el caso de Milagro
}

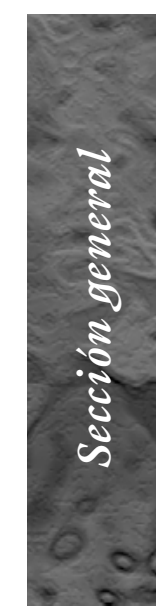

Urbanization in Ecuador and the Importance of State Planning in Creating an Intermediate City (2007-2017): The Case of Milagro

A urbanização no Equador e a importância do planejamento estatal na construção de uma cidade intermediária (2007-2017): o caso de Milagro

María Pilar Castro Herrera* Humberto Miranda **

Recibido: 3 de junio del 2020 Aprobado: 18 de agosto del 2020

https://doi.org/10.12804/revistas.urosario.edu.co/territorios/a.9202

\section{Para citar este artículo:}

Castro Herrera, M. P., \& Miranda, H. (2021). La urbanización en Ecuador y la importancia de la planificación estatal en la creación de una ciudad intermedia (2007-2017): el caso de Milagro. Territorios, (44), 113-141. https://doi.org/10.12804/revistas.urosario.edu.co/territorios/a.9202

* Universidade Estadual de Campinas. Correo electrónico: mpcastroberrera@gmail.com. ORCID: https://orcid.org/00000002-1760-1385

** Universidade Estadual de Campinas. Correo electrónico: bumbmn@unicamp. br. ORCID: http://orcid. org/0000-0001-56582909 
Palabras clave

Planificación estatal; ciudades intermedias; red urbana; planes territoriales; Milagro (Ecuador).

Keywords

State planning; intermediate cities; urban network; territorial plans; Milagro (Ecuador).

Palavras-chave

Planejamento estatal; cidades intermediárias; rede urbana; planos territoriais; Milagro (Equador).

territarios 44

\section{RESUMEN}

La implementación de la política de planificación del Ecuador alcanzó una etapa importante en la reorganización territorial en el periodo 2007-2017. El objetivo de este documento es discutir el fortalecimiento de las ciudades intermedias como uno de los principales efectos de esta política. Para ello, primero se realiza un breve análisis del proceso histórico de la urbanización ecuatoriana, que muestra las dificultades causadas por la constitución de una red urbana vertical con pocas ciudades medianas. Luego, se analiza cómo los planes de descentralización y las medidas de desconcentración implementadas por la política de planificación nacional contribuyeron a reforzar la posición de Milagro en la red urbana del Ecuador. Por último, en las consideraciones finales, se señalan las contribuciones relevantes de la planificación estatal para fortalecer la red urbana en Ecuador.

\section{Abstract}

The implementation of the planning policy reached an important stage in the territorial reorganization of Ecuador in the period 2007-2017. The objective of this document is to discuss the strengthening of intermediate cities as one of the main effects of this policy. For this, first, a brief analysis of the historical process of Ecuadorian urbanization is carried out, which shows the difficulties caused by the constitution of a vertical urban network, with few medium-sized cities. Then, it analyzes how the decentralization plans and the deconcentration measures implemented by the national planning policy contributed to reinforcing Milagro's position in the urban network of Ecuador. In the final considerations, the relevant contributions of state planning to strengthen the urban network in Ecuador are pointed out.

\section{RESUMO}

A implementação da política de planejamento alcançou uma etapa importante da reorganização territorial do Equador no período 2007-2017. O objetivo deste trabalho é discutir o fortalecimento das cidades intermediárias como um dos principais efeitos dessa política. Para isso, primeiramente, é realizada uma breve análise do processo histórico de urbanização equatoriana, que mostra as dificuldades ocasionadas pela constituição de uma rede urbana vertical, com poucas cidades de médio porte. Em seguida, analisa como os planos de descentralização e as medidas de desconcentração implementadas pela política de planejamento nacional contribuíram para reforçar a posição da cidade de Milagro na malha urbana do Equador. Nas considerações finais, são indicadas as contribuições relevantes do planejamento estatal para o fortalecimento da rede urbana do Equador. 


\section{Introducción}

Ecuador, como la mayoría de los países latinoamericanos, se caracteriza por desarrollar una economía extractiva-exportadora y centralizada, manteniendo su patrón de crecimiento en la producción y exportación de petróleo y productos agrícolas. Su capacidad industrial, aún en la actualidad, es muy limitada si se le compara con otros países de la región como Argentina, Brasil, e incluso, su vecino más próximo, Colombia.

En el 2007, con la llegada de un nuevo gobierno, el país apostó por la transformación de su modelo de desarrollo y la reestructuración democrática, como estrategia para enfrentar las profundas crisis económicas y financieras, reveses sociales y crisis de gobernanza que dejó la implementación de políticas económicas neoliberales durante la década de 1990.

Este nuevo gobierno, "el gobierno de la Revolución Ciudadana" dirigido por el expresidente Rafael Correa Delgado, implementó un cambio importante en la estructura y el funcionamiento del Estado, fortaleciendo su papel en la sociedad al recuperar sus funciones estratégicas y llevar a cabo la modificación de normativas y reformas institucionales. Tales reformas se iniciaron con la creación de una nueva Constitución, elaborada a través de una Asamblea Nacional Constituyente en el 2008, la cual se convirtió en base legal para las transformaciones posteriores.
Una de las principales reformas establecidas en el periodo 2007-2017, fue la adopción de la planificación nacional como política de Estado. Así, a través de instrumentos, programas y proyectos, se buscó la reorganización territorial y la redistribución de recursos para servir y promover localidades de manera más equitativa. Con este fin, se implementaron los procesos de desconcentración y descentralización de competencias, lo que cambió la importancia de los gobiernos locales y sus formas de planificación, otorgándoles mayor autonomía en la planificación de su desarrollo. En tal sentido, una de las repercusiones más importantes ocurrió, sobre todo, en el sistema de ciudades, algunas aumentando su influencia dentro de la región donde están insertas y en el sistema urbano nacional en su conjunto.

Por lo tanto, el propósito de este artículo es discutir la aparición de ciudades intermedias como uno de los principales efectos de esta política. Además, el objetivo es proporcionar información analítica y reflexiva sobre cómo el proceso de planificación ecuatoriano ha generado cambios en el desempeño de algunas ciudades, ya que en los estudios oficiales de la red urbana ecuatoriana estos aún carecen de interés.

De este modo, el análisis de la ciudad de Milagro se considera un estudio de caso con el fin de ilustrar los cambios en el sistema urbano ecuatoriano durante 
la implementación del nuevo modelo de planificación nacional. Esta ciudad fue elegida para el estudio tanto por la posición histórica que representa dentro de la economía nacional, como por su desempeño en la red urbana dentro de la región en la que se encuentra. Se dice que el cambio principal que tuvo lugar con Milagro fue su consolidación como ciudad intermedia, al absorber la función de centro administrativo y aprovechar su ubicación geográfica estratégica en relación con Guayaquil, la capital económica del país, y Quito, la capital política de la república.

\section{La importancia de la ciudad intermedia: una breve visión teórica}

El enfoque adoptado en este artículo fueron los cambios más intensos en las jerarquías urbanas desde 1990. Algunas ciudades comenzaron a revelar su poder mediador en áreas no metropolitanas de América del Sur, ya que tienen una economía orientada hacia el sector capitalista agroexportador o dado que son áreas del interior rural que dependen del gasto y las inversiones públicas (Lavinas \& Ribeiro, 1991; Macedo \& Morais, 2011; Orair, 2016; E. Porto, 2003; L. R. Porto, 2016).

En general, después de 1990 la aparición de ciudades intermedias se asoció con dos movimientos simultáneos: por un lado, la expansión económica de las zonas de producción agrícola y mineral en la década de 1990, y por el otro, el crecimiento del gasto público en los gobiernos progresistas de varios países de América del Sur en la década del 2000. El primero fue impulsado por el crecimiento de las exportaciones de bienes primarios y tendió a crear mayores aglomeraciones urbanas en las ciudades del interior; el segundo, fue estimulado por la mayor provisión de equipos, bienes y servicios públicos en las ciudades con la posición más baja en la jerarquía urbana nacional.

Según algunas fuentes en la literatura, el factor clave para generar procesos de urbanización equilibrados - desarrollo urbano sostenible - son las ciudades intermedias, "pues están activas en las redes de ciudades, constituyendo los nodos de la urbanización, intermediando entre otras ciudades y, en especial, entre los flujos globalizados y los territorios concretos" (Llop \& Vivanco Cruz, 2017, p. 48). En otras palabras, son nódulos de equilibrio en la red de ciudades (Ramos et al., 2011).

El papel de las ciudades medianas también se discutió ampliamente en Brasil (Amorim Filho \& Valente, 2001; Corrêa, 2007, 2017; Sposito, 2007). Corrêa $(2007,2017)$, por ejemplo, llama la atención sobre la ciudad mediana como un "nodo" importante en una red urbana, donde es posible pensarla en interacción con otras ciudades en un contexto regional dado, ejerciendo ciertas funciones de manera combinada: "función de lugar 
central, drenaje y consumo de tierras, industrial, ingresos portuarios y función del capital político-administrativo" (2017, p. 30). Por otra parte, Sposito (2007) argumenta que la clasificación de "ciudad intermedia" es más útil para designar de manera apropiada el papel que estas ciudades realmente juegan en un área de influencia.

Con base en estos análisis, se puede decir que las ciudades intermedias son una categoría de ciudades relacional-territorial vistas desde la formación histórica, el tamaño de la población y la influencia espacial, que establece niveles de intermediación intrarregional, extrarregional y contempla otras escalas y jerarquías de ciudades. Por lo tanto, no deben entenderse como una simple derivación del concepto de ciudades medianas, cuyo criterio principal de diferenciación es el tamaño de la población para distinguirlas de las ciudades pequeñas $(+\mathrm{O}$-por debajo de 50 mil habitantes) y grandes (+ o-más de 250 mil habitantes).

Según la visión teórica establecida en este análisis, existen tres características que califican a las ciudades intermedias como una categoría relacional-territorial: la histórica, que muestra el contexto económico-espacial de su origen en los países y regiones donde ocurrió el proceso de urbanización en modo disperso territorialmente (Carrión, 1985; Pradilla, 1993; Santos, 2010; Singer, 1973); teórico, que surge de los enfoques que considera las escalas espaciales, locales, regionales e internacionales que interactúan permanentemente en una economía globalizada y sus impactos en América Latina (Brandão, 2018); y el empírico, en la medida en que acompaña el proceso de jerarquización de las redes urbanas que penetran en el interior del territorio, operando como una base logística para ordenarlo (Becker, 2005).

En el contexto ecuatoriano, si bien la investigación sobre el sistema de ciudades ha sido objeto de estudios en diferentes momentos de la historia del país, la investigación sobre las ciudades intermedias y su papel dentro de la red urbana aún es un área de exploración, esto se debe principalmente al enorme peso demográfico, económico, social y político que tienen las principales ciudades del país, así como el desinterés aparente que los estudios urbanos habrían presentado desde el inicio del nuevo siglo, resultado de las mudanzas en las orientaciones de las políticas públicas en lo nacional y local (Bermúdez et al., 2016). Sin embargo, producto de los mismos cambios y orientaciones políticas tanto locales como de orden internacional - suscripción de los Objetivos de Desarrollo Sostenible (ODS) en el 2015 - traen de nuevo a la palestra la discusión sobre la cuestión urbana y la construcción de políticas públicas orientadas al desarrollo sostenible de las ciudades.

En este sentido, en el escenario actual no puede abordarse el fenómeno urbano sin considerar el papel que desempeñan territarias 44

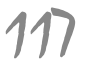


las ciudades intermedias dentro de la red urbana de cada país, y más, cuando las funciones de estas se tornan decisivas al momento de implementar procesos de ordenamiento territorial - descentralización y desconcentración-, procesos implementados en el Ecuador en la última década como parte de la política de planificación nacional, enmarcado en la lógica de restructuración democrática y de transformación del modelo de desarrollo.

\section{El proceso de urbanización ecuatoriano y la verticalización de su red urbana}

En la actualidad, Ecuador tiene una población estimada de 17,3 millones de habitantes (2020), una superficie total de $256,37 \mathrm{mil} \mathrm{km}^{2}$ y está compuesto por 24 provincias (figura 1). Su PIB, según el criterio de paridad del poder adquisitivo (PPA), fue de aproximadamente 185 mil

Figura 1. División política del Ecuador

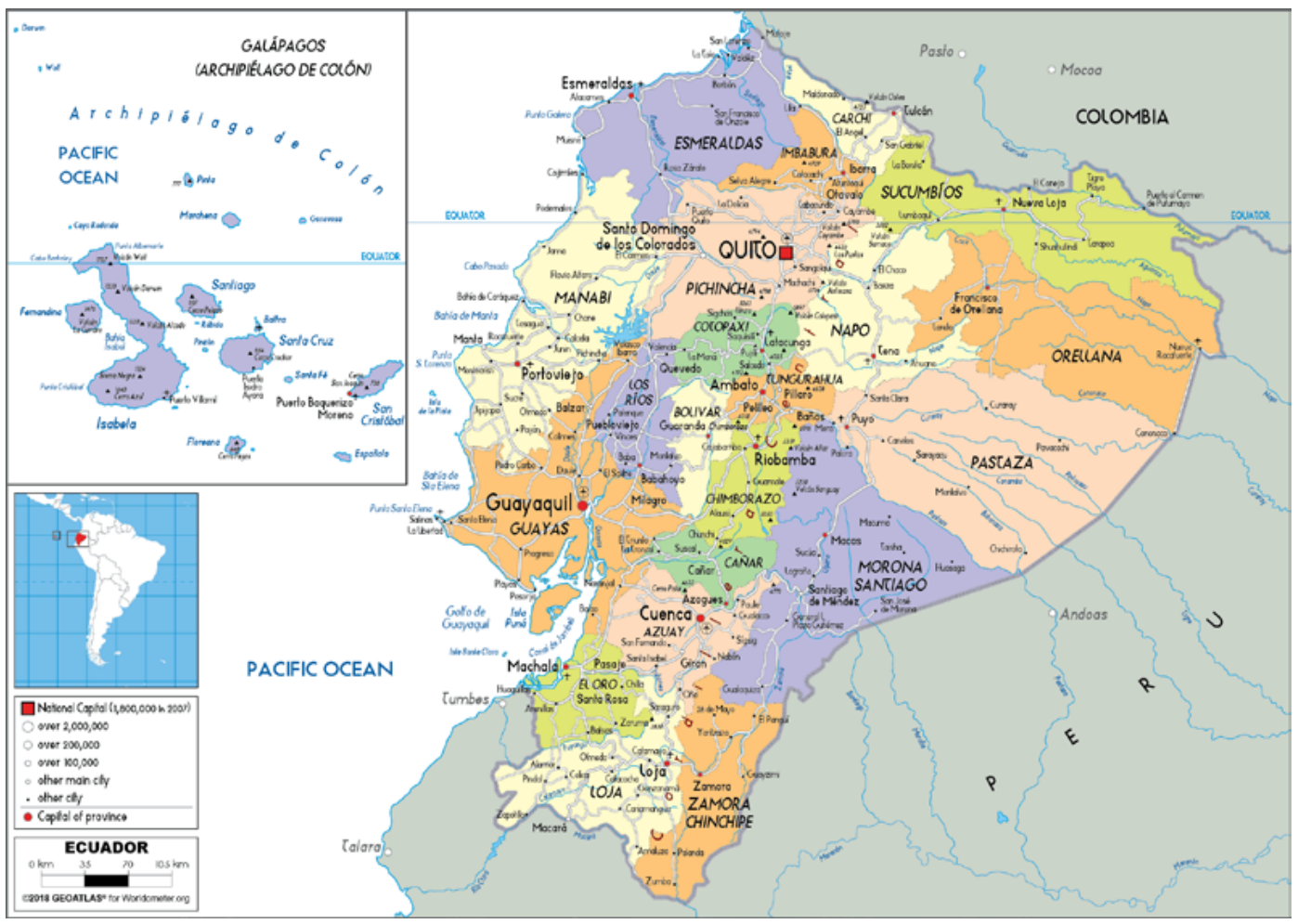

Fuente: Worldometer (s.f.). 
millones de dólares (2020). El petróleo es el principal producto, representando el $40 \%$ de las exportaciones del país, además de ser un importante productor y exportador de bananas, flores y cacao. La industria se concentra principalmente en la ciudad de Guayaquil, que también es el centro de negocios más grande del país. Quito, la capital, tiene una economía centrada esencialmente en el servicio público y, además de ser el centro financiero y político del Ecuador, es uno de los principales destinos turísticos internacionales. Hasta el 2010, según el Instituto Nacional de Estadísticas y Censos (INEC), el Ecuador tenía 13 ciudades con más de 100 mil habitantes, dos de ellas, Guayaquil y Quito, con más de 2 millones.

Los procesos urbanos en los países latinoamericanos tienen ciertas similitudes en su formación, Ecuador no es la excepción. La mayoría de estos procesos fueron determinados por el dinamismo de los fenómenos económicos, políticos y sociales de cada territorio, que difieren de los procesos urbanos en regiones más desarrolladas como Europa y América del Norte, quienes están centrados fuertemente en la industrialización de sus economías. Sin embargo, la aceleración y consolidación de los procesos de urbanización latinoamericanos, se debe a la asociación de sus economías con diferentes formas de conexión con el capitalismo mundial. Es decir, los procesos urbanos latinoamericanos no se basaron directamente en la industrialización, sino que respondieron las necesidades y requerimientos del capitalismo mundial (Achig, 1983).

Para Pradilla y Márquez (2016), después de la Segunda Guerra Mundial, el proceso de industrialización en América Latina siguió tres características, fue desigual, tardío y transnacionalizado. Según ellos:

No incluyó a todos los países, pues básicamente se industrializaron Argentina, Brasil, México y, en menor medida, Perú, Colombia y Chile, mientras que los países pequeños como los centroamericanos, Paraguay, Bolivia y Ecuador, tuvieron que esperar aún varias décadas para que ella iniciara; y en todos los casos, el resultado fue muy desigual (Pradilla \& Márquez, 2016, p. 22).

En Ecuador este proceso se dio primero, a través del desarrollo de actividades primario-exportadoras ${ }^{1}$ (1870-1960), luego, con el ingreso de la economía al proceso industrial con el petróleo (1960). Ambos procesos bajo políticas gubernamentales concentradoras y excluyentes que beneficiaban ciertas regiones y segregaban a otras. Consolidándose así, las bases de la polarización urbana existente hasta la actualidad: ciudades extremadamente grandes (adaptado a la realidad ecuatoriana) como Quito y Guayaquil, concentradoras de recursos y de población $\mathrm{y}$, de ciudades pequeñas con problemas de organización, planificación,
${ }^{1}$ Actividades económicas de exportación de cacao y banano. 
${ }^{2}$ Las dos primeras en periodos de dictadura militar y la última a través de Consejo de Gobierno.

${ }^{3}$ Según datos del INEC, durante la crisis y después de ella, aproximadamente 800 mil personas con el estatus de migración salieron del país con destino principal a los Estados Unidos y Europa.

\section{territarios 44}

carentes de recursos públicos y con altos índices de desigualdad.

Otro de los factores que fomentó la urbanización ecuatoriana fueron las reformas agrarias implementadas en 1964 , 1973 y $1979 .{ }^{2} \mathrm{El}$ ingreso de su economía a la actividad petrolera en 1970 , favoreció el crecimiento de las grandes ciudades al fomentar la actividad industrial y potenciar el desarrollo de otras. No obstante, su aporte en la reducción de las desigualdades locales y regionales fue exiguo, siendo que los índices se agudizaron profundizando aún más la polarización en los mismos ejes urbanos, configurados como polos de migración y concentradores de riqueza (Bocco, 1983).

El proceso de urbanización del país registra otros momentos trascendentales durante la década de los años 90, tal como el fenómeno natural de "El Niño" (1997), que dejó grandes pérdidas y deudas al sector rural del país y, la crisis financiera del final de siglo pasado que generó la mayor ola migratoria ${ }^{3}$ suscitada en los últimos tiempos, así como la pérdida de la soberanía financiera y monetaria del país, adoptando el dólar como moneda oficial, tuvieran influencia directa o indirecta.

Estos dos últimos eventos hicieron que el Ecuador se moviera de un país predominantemente rural a un país urbano, lo que profundizó aún más los desequilibrios y desigualdades ya existentes entre localidades y regiones. Después de la década de los años 90 , el crecimiento urbano - especialmente en las principales ciudades-, redujo su ritmo modificando incluso la dirección de la migración, de rural-urbana a urbana-urbana (Castro, 2019), creando así los problemas estructurales en las ciudades.

Sobre el tema de los saldos migratorios, los datos del censo (2010) mostraron que existe un desequilibrio muy marcado entre los espacios de atracción y la expulsión de la población. Según el Instituto Geográfico Militar (IGM, 2013), la mayoría de las localidades en la región de Sierra (71\%) tienen un saldo negativo, de 507 localidades, 359 tenían un saldo migratorio negativo y 148 positivas, siendo la Provincia de Pichincha y la ciudad de Quito los que atraen más población. En la región de la Costa, de 305 localidades, $173(57 \%)$ son positivas y $132(43 \%)$ negativas, siendo la provincia de Guayas y la ciudad de Guayaquil las más atractivas. En la Amazonía, de 203 localidades, 161 (79\%) son positivas y $42(21 \%)$ negativas, la mayoría de las ciudades con un saldo positivo ubicadas en áreas petroleras (Nueva Loja, Puerto Francisco de Orellana y Shushufindi). Milagro y otras ciudades alrededor de Guayaquil presentan saldo positivo (IGM, 2013).

La figura 2 muestra la evolución de la población por lugar de residencia, con énfasis en el rápido crecimiento de la población urbana. El país que hasta 1990 tenía el $39 \%$ de la población viviendo en el espacio urbano, a principios de siglo Xx, entre el 2001 y el 2010 , aumentó 
Figura 2. Evolución de la población rural y urbana en el periodo 1950-2010

- Urbano Rural

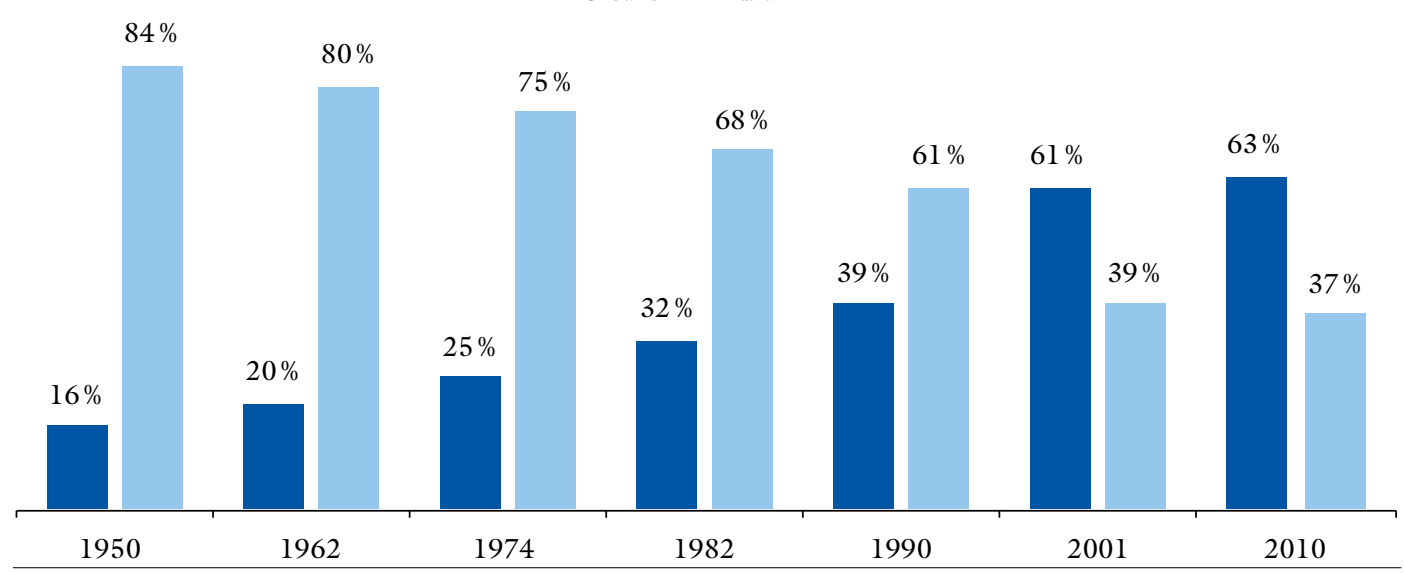

Fuente: INEC (2010).

al $61 \%$ y al $63 \%$ de la población total, respectivamente. La población rural disminuyó considerablemente, como parte de los graves efectos que la crisis y otros factores descritos causaron a la dinámica de la población del país.

En este sentido, se puede inferir que, durante este periodo de ajustes y crisis las ciudades pequeñas y medianas ganaron población en relación con las grandes, ya sea por crecimiento vegetativo o por ser el destino preferido para las migraciones internas. Esto puede interpretarse como un cambio en la tendencia migratoria, ya que antes (periodos de picos y crisis de agro-exportación) las ciudades que concentraban la mayor cantidad de población eran las más grandes, como Quito y Guayaquil - y otras más, dependían del ciclo económico del momento-, pero actualmente, esa situación está cambiando.
Ya está claro que el aumento de la tasa de urbanización se produce en todo el país.

En síntesis, el sistema urbano ecuatoriano siempre se vio influenciado por las alteraciones en su padrón de desarrollo, sea a través de las actividades primarioexportadoras, el proceso de industrialización o crisis financieras. Por lo tanto, si por un lado se tenía un país predominantemente rural que se estaba convirtiendo cada vez más en una sociedad urbana después de la década del 2000, por otro lado, no se sabe en qué medida esta situación contribuye a la estructuración y consolidación de una red urbana nacional.

\section{Características de la red urbana ecuatoriana}

Una red urbana completamente formada en un país debe expresar un conjunto de 
centros urbanos funcionalmente articulados (Corrêa, 2006). De acuerdo con Santos (2008), cuando "se quer conhecer a realidade viva da economia urbana, é preciso considerar o conjunto de células urbanas de uma dada região, assim como o organismo que elas formam no país" (p. 157). Estos parámetros son importantes para tener un nivel jerárquico de articulación en los centros urbanos y revelar un grado de especialización entre los centros, de modo que la red urbana gane complejidad. Especificamente, Corrêa afirma que:

A rede urbana, por outro lado, pode caracterizar-se por diferentes formas espaciais de suas unidades funcionais: área metropolitana, isto é, uma metrópole e suas cidades-dormitórios e núcleos especializados fisicamente interligados; aglomeração urbana pela geminação de duas ou mais cidades de mesmo porte ou como miniatura de uma área metropolitana; cidadedispersa, constituída por um conjunto de cidades muito próximas umas das outras e dotado de funções especializadas e complementares entre si, caracterizando um desdobramento espacial de funções urbanas; cidades medias e pequenas cidades e minúsculos locais em torno de um ou mais estabelecimentos comerciais e de serviços. A presença de todas estas formas indica a complexidade funcional da rede urbana (Corrêa, 2006, pp. 44-45).

\section{territarias 44}

Con respecto a los países de América Latina, es importante enfatizar que, como indicó Santos (2008), "na maioria dos casos, a hierarquia continua flutuante, instável, e reflete, até certo ponto, a luta entre a economia nacional e o domínio estrangeiro" (p. 162). Este sería el caso de la mayoría de los países de América del Sur, incluido Ecuador, como resultado de la fuerte dependencia del sector de comercio exterior y divisas.

Como se ve desde el comienzo de la sección, el proceso de transición rural-urbano se completó en Ecuador recientemente, en el siglo XXI. Las dos ciudades principales, Quito y Guayaquil, son también las metrópolis nacionales y todo lo demás sigue las características de la ocupación histórica, la formación económica y, principalmente, las características naturales (figura 3). Al oeste está la región de la Costa ecuatoriana, que es plana y de baja altitud, donde se encuentra su ciudad más importante, Guayaquil; —así como la ciudad de Milagro ubicada en la zona occidental de la provincia del Guayas-, en el centro del país, de norte a sur, está la parte ecuatoriana de los Andes, la Sierra, con grandes altitudes (algunos de los picos alcanzan más de 6000 metros) y varios volcanes, allí se encuentra la capital Quito y otras ciudades importantes; al este del país, en la parte oriental, se ubica la Amazonía ecuatoriana, que tiene un clima cálido y húmedo, donde se ubican las ciudades de Nueva Loja y Puerto Francisco de Orellana; y finalmente, la región Insular, donde se encuentran las Islas Galápagos. 
Figura 3. Regiones, provincias y ciudades del Ecuador

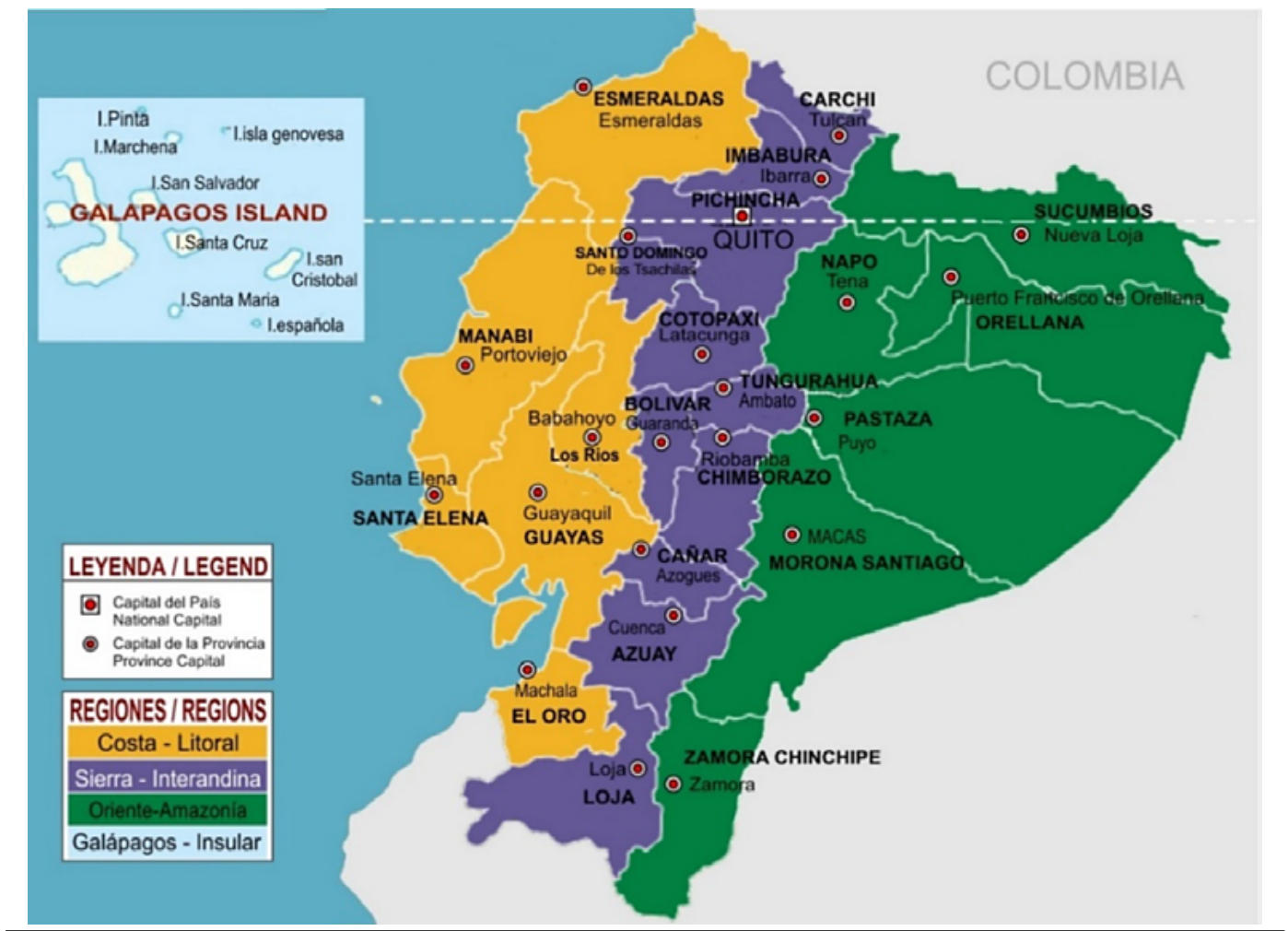

Fuente: Ramírez (2017).

La dolarización de la economía ecuatoriana en enero del 2000 , decretada por el presidente Jamil Mahuad Witt, resultó en la estabilidad monetaria y, al mismo tiempo, en el aumento de la vulnerabilidad externa, pues el país se vio obligado a fortalecer un modelo de especialización productiva y territorial basado en las exportaciones de productos básicos. Esto condujo a la ocupación económica de espacios más alejados de la Costa y la Sierra, como la Amazonía, por ejemplo. Las implicaciones de esto para la red urbana de Ecuador fueron, como lo sugieren Corrêa (2006) y Santos (2008), además del aumento en la tasa de urbanización nacional, el cambio en las jerarquías urbanas regionales y la mayor dispersión del conjunto de ciudades en todo el territorio.

Con base en estas características, se puede decir que la red urbana ecuatoriana es muy incipiente y altamente verticalizada por Quito, en la región de Sierra, 
Guayaquil y en la región de la Costa. Pero la red urbana del Ecuador está más dispersa hoy en su conjunto de centros urbanos que en el pasado. Al considerar la distribución de la población por las cuatro regiones naturales del país (Costa, Sierra, Amazonía e Insular), se observa en la figura 4 que hay una concentración de más del $90 \%(96,2 \%)$ de la población en dos de ellos, Sierra y Litoral, debido a sus características históricas y espaciales de ocupación.

Las proyecciones de población para el 2020, realizadas por la Secretaría Técnica Planifica Ecuador (antes Senplades) y el INEC, indican que la región de la Sierra mantendrá la tasa de urbanización estable, pero la provincia de Loja aumentará la tasa de urbanización de 55,0 a 65,0\%; la región de la Costa aumentará la tasa de urbanización del 71,3 al 73,9\%, con la provincia de Esmeraldas teniendo el aumento más significativo del 49,0 al 63,7\%; en la Amazonía, la tasa de urbanización regional proyectada es la más alta, pasando de 38,6 a 43,0\%, con la provincia de Orellana teniendo el aumento más expresivo de todos, de 40,4 a $56,2 \%$, según las proyecciones. La región Insular será la única que tendrá una caída significativa en la tasa de urbanización del 82,9 al $54,3 \%$. Esto puede confirmarse por el número de centros urbanos con más de 10 mil habitantes desde 1990, según la figura 5 .

A su vez, como se observa en la figura 5 , hay un salto en el número de ubicaciones con más de 10 mil habitantes de 49 a 65 entre 1982 y 1990, y en el periodo 1990-2010 hubo 44 ubicaciones más. Entre el último y el penúltimo censo, surgieron 25 ubicaciones más, y de ellas, 16 pertenecen a las regiones de Amazonía e Insular. Estas proyecciones indican una

Figura 4. Distribución de la población por regiones naturales en el 2001 y el 2010

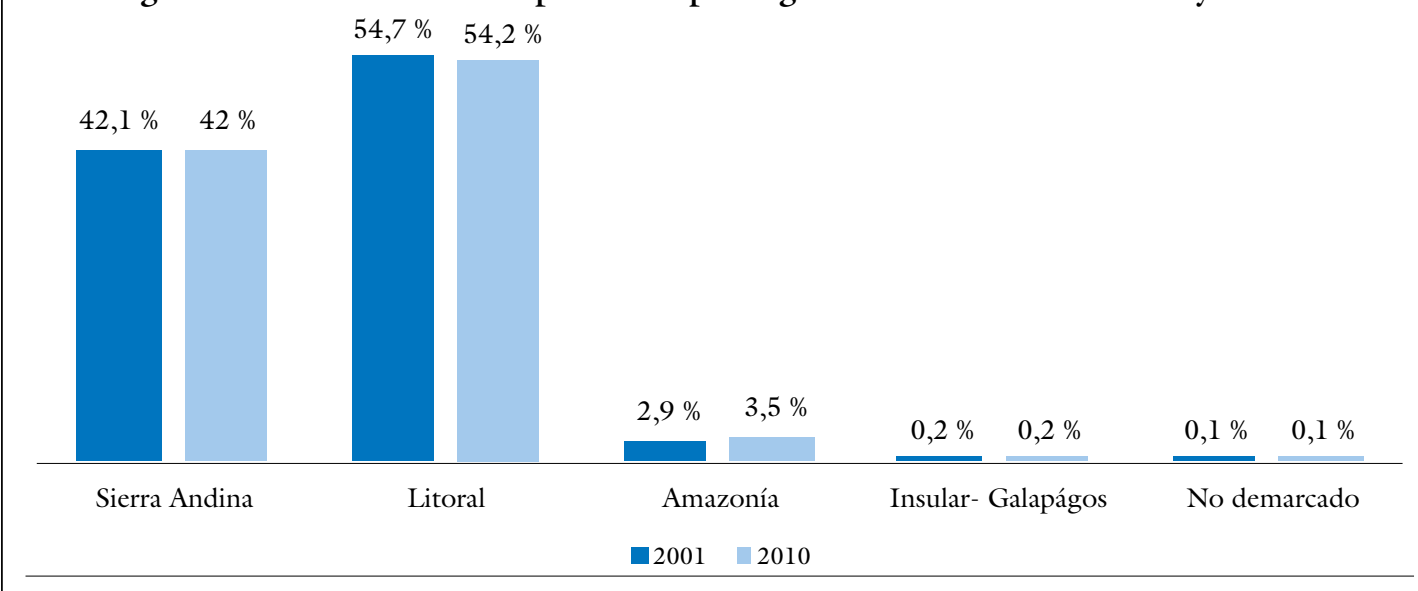


Figura 5. Número de localidades por regiones naturales según el censo 1950-2010 (+10mil habitantes)

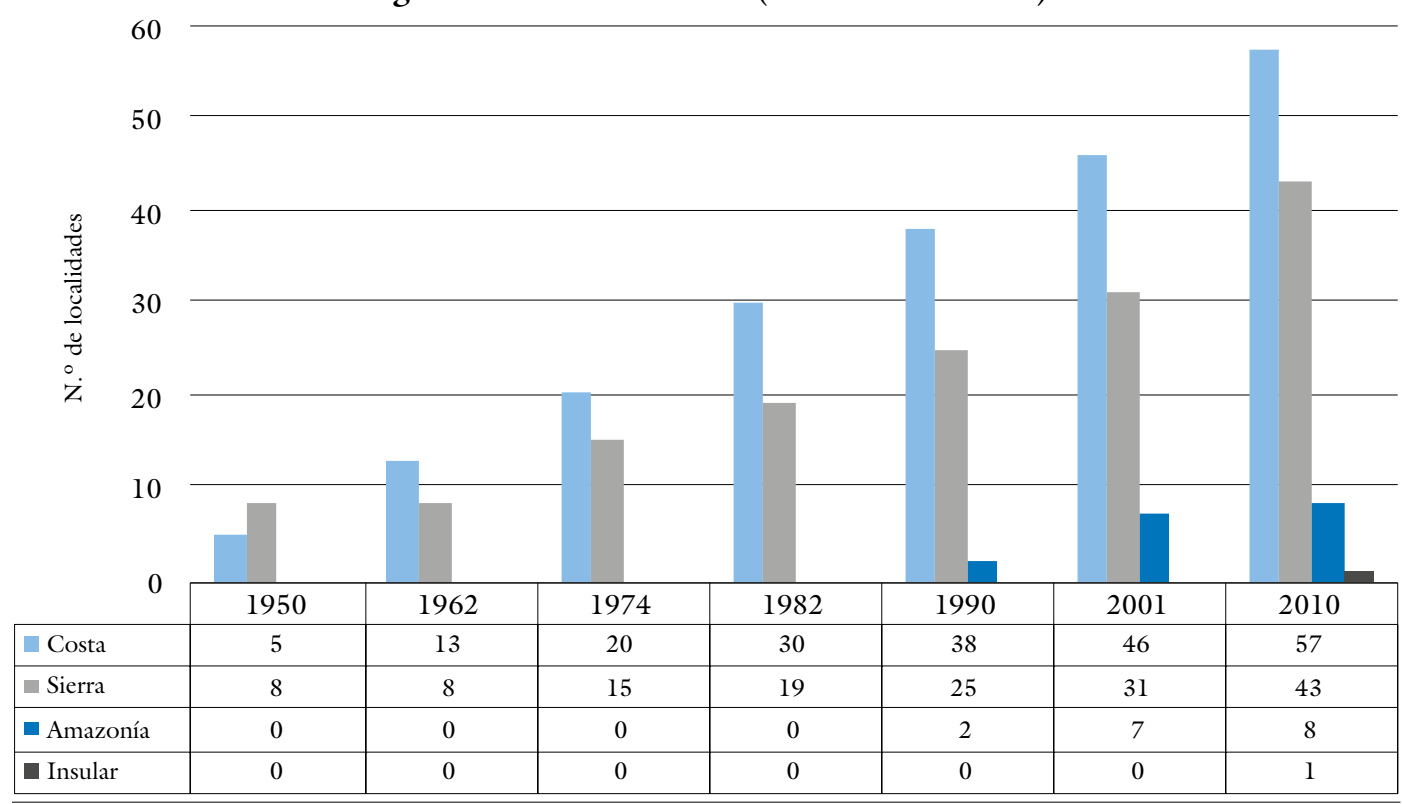

Fuente: IMG (2013).

tendencia de dispersión en los centros urbanos de Ecuador en los próximos años.

Por su parte, el INEC (2010) mostró cuáles son las 11 ciudades consideradas intermedias de un total de 224 que comprenden el territorio ecuatoriano. Riobamba, Esmeraldas, Milagro, Ibarra, Loja, Babahoyo, Quevedo, Rumiñahui, Ambato, Santa Elena y La Libertad, juntas, concentran el $14 \%$ del total de la población nacional. Con una tasa de crecimiento medio por encima del $21 \%$ entre el periodo 2001 y el 2010 , superan la media de crecimiento de las ciudades grandes que es $20,8 \%$, e incluso, de las metrópolis $17 \%$. Lo cual nos proporciona una visión clara de mudanzas en las tendencias urbanas del país.

En vista de lo anterior, han surgido estudios sobre la caracterización actual de la red urbana en Ecuador. Tal es el caso del Informe Nacional de Ecuador para la Tercera Conferencia de las Naciones Unidas sobre Vivienda y Desarrollo Urbano Sostenible (HABITAT III), que presenta una serie de datos económicos, sociales y espaciales importantes y muestra cómo se distribuye la población en el territorio (tabla 1), según las categorías de ciudades - metrópolis, ciudad grande, ciudad mediana y ciudad pequeña- Hay una caída en la participación relativa de 
Tabla 1. Distribución poblacional en el territorio (2001-2010)

\begin{tabular}{|c|c|c|c|c|}
\hline \multirow{2}{*}{ Categoría } & \multicolumn{4}{|c|}{ Distribución poblacional } \\
\hline & \multicolumn{2}{|r|}{2001} & \multicolumn{2}{|r|}{2010} \\
\hline $\begin{array}{l}\text { Ciudad metrópoli } \\
(2)\end{array}$ & $43 \%$ & Guayaquil y Quito. & $41 \%$ & Guayaquil y Quito. \\
\hline $\begin{array}{l}\text { Ciudad grande } \\
\text { (6) }\end{array}$ & \multirow{3}{*}{$57 \%$} & $\begin{array}{l}\text { Cuenca, Machala, Portoviejo, } \\
\text { Manta, Ambato y Santo } \\
\text { Domingo ( } 6 \text { ciudades })\end{array}$ & \multirow{3}{*}{$59 \%$} & $\begin{array}{l}\text { Cuenca, Machala, Portoviejo, } \\
\text { Manta, Durán y Santo } \\
\text { Domingo ( } 6 \text { ciudades })\end{array}$ \\
\hline $\begin{array}{l}\text { Ciudad mediana } \\
\text { (11) }\end{array}$ & & $\begin{array}{l}\text { Riobamba, Esmeraldas, Milagro, } \\
\text { Ibarra, Loja, Babahoyo, Quevedo, } \\
\text { Durán, Latacunga, La Libertad } \\
\text { y Santa Elena (11 ciudades). }\end{array}$ & & $\begin{array}{l}\text { Riobamba, Esmeraldas, Milagro, } \\
\text { Ibarra, Loja, Babahoyo, Quevedo, } \\
\text { Rumiñahui, Ambato, Santa Elena } \\
\text { y La Libertad ( } 11 \text { ciudades). }\end{array}$ \\
\hline $\begin{array}{l}\text { Ciudad pequeña } \\
(202 \text { a } 205)\end{array}$ & & $\begin{array}{l}\text { Son } 202 \text { ciudades. Top } 10 \text { en } \\
\text { población: Otavalo, Tulcán, } \\
\text { Chone, Pasaje, Santa Rosa, } \\
\text { Jipijapa, Daule, Lago Agrio, } \\
\text { Huaquillas y Quinindé. }\end{array}$ & & $\begin{array}{l}\text { Son } 205 \text { ciudades. Top } 10 \text { en } \\
\text { población: Otavalo, Latacunga, } \\
\text { Daule, Salina, Pasaje, } \\
\text { Tulcán, Chone, Montecristi, } \\
\text { Quinindé y Santa Rosa. }\end{array}$ \\
\hline
\end{tabular}

Fuente: MIDUVI/SHAH (2015).

la población de las metrópolis y un aumento proporcional en la participación de ciudades grandes, medianas y pequeñas, agregadas entre el 2001 y el 2010. El criterio de población tiene grandes limitaciones, pero muestra el peso creciente de las aglomeraciones no metropolitanas.

En su tesis, Menoscal (2017) avanza en el análisis yendo más allá del criterio poblacional al incrementar la intensidad de los flujos varios entre las ciudades, lo que permite con mayor claridad observar el papel de las ciudades intermedias en el Ecuador conforme la figura 6.

El autor señala las características comunes que califican a Quevedo y Milagro como ciudades intermedias, indicando lo siguiente:
Estas ciudades a más de pertenecer a la zona del pre litoral ecuatoriano, comparten una serie de características similares, tanto en ubicación, estructura y crecimiento urbano, fuentes económicas, así como también de características físicas, morfológicas y ambientales, haciéndolas idóneas para ser seleccionadas como casos de estudio, ya que son comparables entre ellas (Menoscal, 2017, p. 50).

Finalmente, llegamos a las características actuales de la red urbana de Ecuador. Aunque incipiente, esta red se ha vuelto más compleja a lo largo de los años, en especial después de las fuertes inversiones públicas realizadas en el periodo 20072017, con la última Constitución que

\section{territarias 44}


Figura 6. Mapa de ciudades grandes e intermedias en el Ecuador para 1990

(Izquierda) y el 2010 (Derecha), e intensidad de flujos en la red vial para el 2015

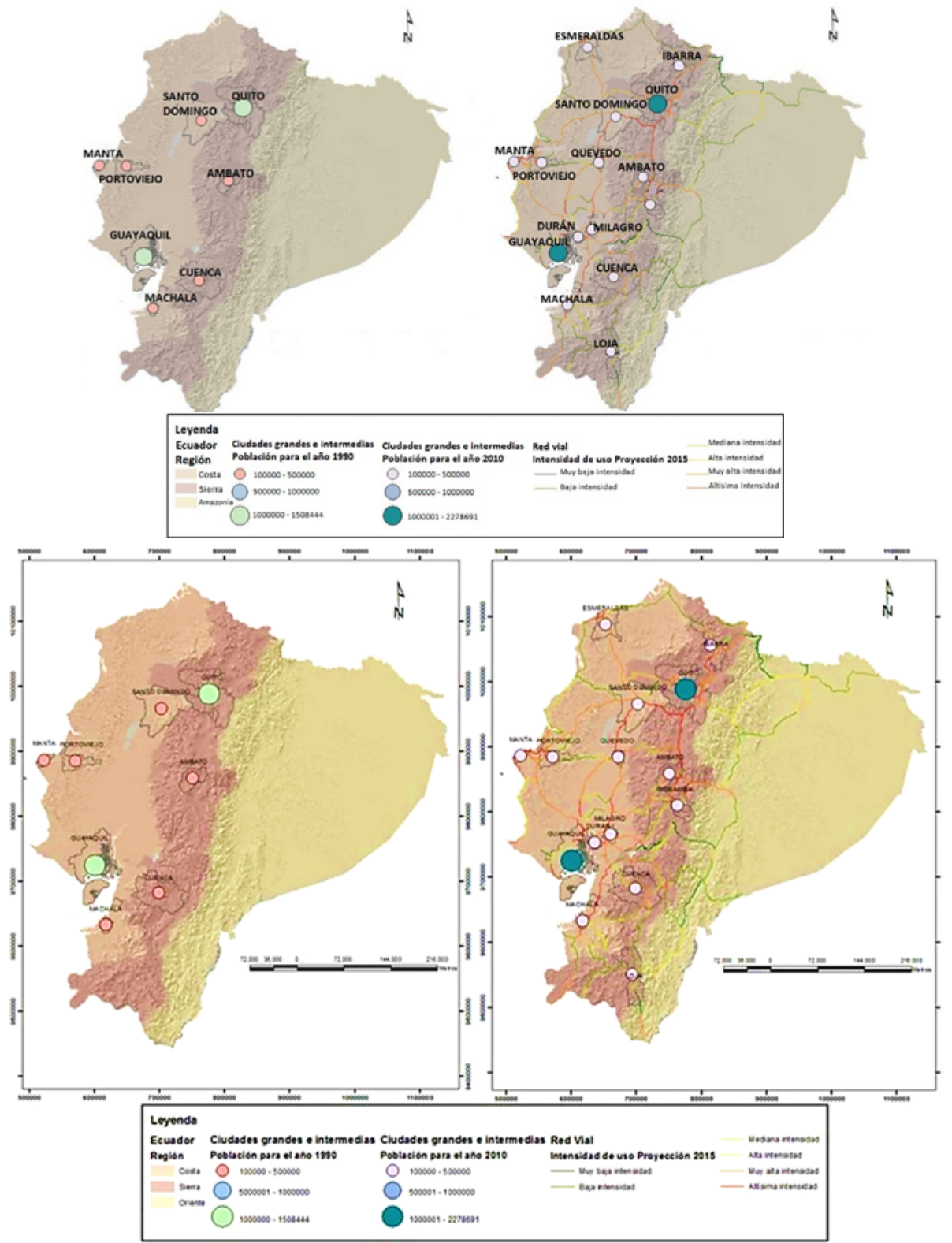

Fuente: Menoscal (2017, p. 46). 
4 Francisco Asan, del Partido Social Cristiano (PSC) (derecha conservadora) y Denisse Robles, del Movimiento Alianza PAÍS (izquierda socialista).

\section{territarias 44} 128 proporciona nuevas funciones a centros de tamaño mediano como la ciudad de Milagro. Sin embargo, antes se abordan las principales reformas de la "Revolución Ciudadana" que permitieron una mayor participación regional y la constitución de planes territoriales.

\section{La política de planificación territorial y el desarrollo de la ciudad intermedia}

Desde 1950, el Ecuador adoptó la planificación como herramienta y pilar fundamental para guiar su desarrollo. Han sido varios los organismos y planes de desarrollo creados y ejecutados desde entonces, todos bajo diferentes visiones de acuerdo con los paradigmas de desarrollo adoptados. Con la nueva Constitución Política de la República del Ecuador del 2008 (art. 3 y 275), la planificación pasó a establecerse como uno de los deberes prioritarios del Estado para el desarrollo nacional, de carácter participativo, descentralizado y desconcentrado que promueve la equidad social y territorial (Constitución Política del Ecuador, 2008).

Con este antecedente, el país pasó por un proceso de restructuración democrática, en el cual se crearon políticas, programas, proyectos, herramientas de planificación y nuevas normas jurídicas. Como parte de los objetivos de esta nueva planificación nacional, se estableció la reorganización territorial como política que incluía la construcción y ejecución de planes de desarrollo y ordenamiento territorial en todos los niveles de gobierno. La implementación de procesos de descentralización ocurrió a través de la transferencia de competencias desde el gobierno central hacia los Gobiernos Autónomos Descentralizados (GAD) - proceso ya implementado en décadas pasadas bajo otros lineamientos, pero con resultados exiguos y sin mayor impacto-. Por otro lado, la desconcentración de servicios públicos, ocurrió a través de la división administrativa del país en zonas, distritos y circuitos de planificación.

En el contexto de la ciudad de $\mathrm{Mi}^{-}$ lagro, durante la década de 2007-2017, fueron dos los Planes de Desarrollo y Ordenamiento Territorial implementados, de aquí en adelante PDOT. El primer plan fue aprobado en el 2011 bajo el mandato de Francisco Asan Wonsang, y su actualización en el 2014 con el mandato de Denisse Robles, ambos gobiernos de diferentes líneas políticas. ${ }^{4}$

La metodología de construcción fue dirigida por la Secretaría Técnica Planifica Ecuador (antes Senplades), mediante acompañamiento institucional. La estructura del primer plan (2011) estuvo determinada por sistemas, mientras que su actualización (2014) se definió por componentes, entre ellos el componente ambiental, biofísico, económico, sociocultural, político-institucional, asentamientos humanos, movilidad, energía y conectividad, así como un componente 
de participación ciudadana (PDOT, 2014). Ambos planes, según la metodología Senplades, cuentan con una propuesta de desarrollo, objetivos estratégicos, indicadores de resultados y de gestión, metas por alcanzar, modelo territorial deseado y modelo de gestión implementado.

Por su parte, la discusión de los procesos de descentralización en el país no son temas actuales, son varios los momentos en la historia de Ecuador donde se han propuesto e implementado, sea por reformas de Estado o por crisis. Está la Ley de Modernización del Estado de 1993 (medida dictada por el consenso de Washington), la Ley Especial de Descentralización del Estado y Participación Social (adoptada en la Constitución de 1998) y la Crisis Financiera de 1999 (Barrera, 2007).

Luego del 2008, con la aprobación de la nueva Constitución y el Código Orgánico de Ordenamiento Territorial y Administración Descentralizada (COOTAD, 2010), un nuevo proceso de descentralización entró a implementarse a través de la transferencia de ciertas competencias desde el gobierno central a los locales. A nivel local y municipal, fueron tres las competencias que se transfirieron: competencia de Tránsito, Transporte Terrestre y Seguridad Vial (TTTSV); competencia de Cooperación Internacional (CI) y competencia de Mantenimiento y Difusión del Patrimonio Cultural; sin contar la regulación de algunas otras.
Respecto del proceso de desconcentración de servicios, este se implementó bajo la estrategia de "El Estado a tu lado", estableciendo una estructuración institucional de la administración pública del país en territorio. ${ }^{5}$ De ese modo, se dividió al país en 9 zonas de planificación, ${ }^{6}$ 104 distritos y 1134 circuitos administrativos con el objetivo de reorganizar la gestión del Estado para garantizar el acceso de servicios de calidad prestados a la ciudadanía, además de planificar y organizar con enfoque territorial la inversión pública. Este proceso se constituyó en el traslado de diferentes facultades y atribuciones desde el nivel central, a los niveles jerárquicamente independientes en territorio, sin dejar de mantener el control central.

Este último proceso constituyó a la ciudad de Milagro como la capital administrativa de zona (zona 5), albergando todas las instituciones públicas que, según la propuesta de Distribución del Ejecutivo en Territorio (DET), se desconcentraron a ese nivel administrativo convergiendo todas en una sola plataforma zonal llamada Centro de Atención Ciudadana (CAC).

Este proceso, como se indicó al comienzo del texto, contribuyó a reforzar el papel de las ciudades intermedias; ya que la población de toda la región consiguió acceso a servicios esenciales de salud, educación, transporte, entre otros, y recibió equipos públicos de agencias estatales que otorgan centralidad a la ciudad,
${ }^{5}$ Decretos Ejecutivos $n{ }^{o}$ 878 del 2008 yn. ${ }^{\circ} 290 \mathrm{del}$ 2012.

- Son 9 zonas de planificación: Zona 1 (Esmeraldas, Imbabura, Carchi y Sucumbios), Zona 2 (Pichincha -excepto el Cantón-Quito, Napo y Orellana), Zona 3 (Cotopaxi, Tungurahua, Chimborazo y Pastaza), Zona 4 (Manabi y Santo Domingo de Tsáchilas), Zona 5 (Santa Elena, Guayas -excepto los cantones de Guayaquil-, Samborondón, Durán, Bolivar, Rios y Galápagos), Zona 6 (Cañar, Azuay y Morona Santiago), Zona 7 (El Oro, Loja y Zamora Chinchipe), Zona 8 (Cantones de Guayaquil, Samborondón $y$ Duran), Zona 9 (Distrito Metropolitano de Quito) (Senplades, 2009).

territorias 44 129 
permitiendo la creación de vínculos con otras ciudades en su área de influencia. Brandão (2017) ha enfatizado este aspecto esencial de la provisión de bienes y servicios colectivos, defendiendo a la ciudad intermedia como una "privilegiada plataforma territorial de articulação da cidadania” (p. 112).

En Ecuador, parte de este proceso también involucró la reorganización de los servicios públicos, donde por criterios técnicos y de población, la ciudad se beneficia de la inversión pública, principalmente en el sector social a través de la construcción de unidades educativas, centros de salud, unidades de policía comunitaria, entre otros. En lo económico, este proceso además de ofrecerle mayor protagonismo a nivel regional y nacional a la ciudad, generó dinamismo económico en lo local, atrayendo nuevas inversiones privadas.

Sin embargo, no es suficiente con solo ofrecer servicios e instalaciones públicas, la oferta necesita compatibilidad con un alto grado de urbanización y una situación de infraestructura vial favorable a la ubicación geográfica de la ciudad dentro del contexto regional específico, para que dichas políticas generen efectos apreciables a múltiples escalas. En este sentido, la ciudad de Milagro cumple los requisitos principales de una categoría intermedia de ciudades, para relacionarse y crear vínculos con localidades dentro y más allá de su cantón, ocupando un mayor papel regional y nacional.

\section{Milagro y su importancia como ciudad intermedia del Ecuador}

Milagro, es un municipio del litoral ecuatoriano localizado en el sector centro-oeste de la provincia del Guayas (figura 7), es la tercera ciudad más grande en población de la misma provincia, con 166,6 mil habitantes y una tasa de crecimiento poblacional anual de 1,93\% según el censo del 2010. Su estructura productiva está basada en la actividad agrícola de la caña de azúcar, cacao, banana y otros productos propios de la zona; posee una de las industrias azucareras más antiguas del país "Ingenio Valdez" con el $30 \%$ de la ocupación del mercado nacional. Su sector de comercio y servicio al igual que el resto de la economía ecuatoriana, resulta el de mayor dinamismo con una demanda laboral del $45,14 \%$ en el sector de servicio y $32,6 \%$ en el sector comercio (INEC, 2010).

Así mismo, Milagro se establece como un centro urbano servidor de bienes y servicios, de interacción social, económica y cultural. Es la tercera fuerza económica de la provincia, después de Guayaquil y Durán, concentrando el $50,74 \%$ de la actividad productiva, el $52,3 \%$ de la actividad industrial, el $60,43 \%$ de las actividades de comercio y el 48,61\% de las actividades de servicio de la subregión donde esta inserida, que comprende los cantones de Yaguachi, Alfredo Baquerizo Moreno, Simón Bolívar, Naranjito y Marcelino Maridueña (INEC, 2010). Su red 
Figura 7. Mapa de localización del Cantón y la ciudad de Milagro en la Provincia de Guayas

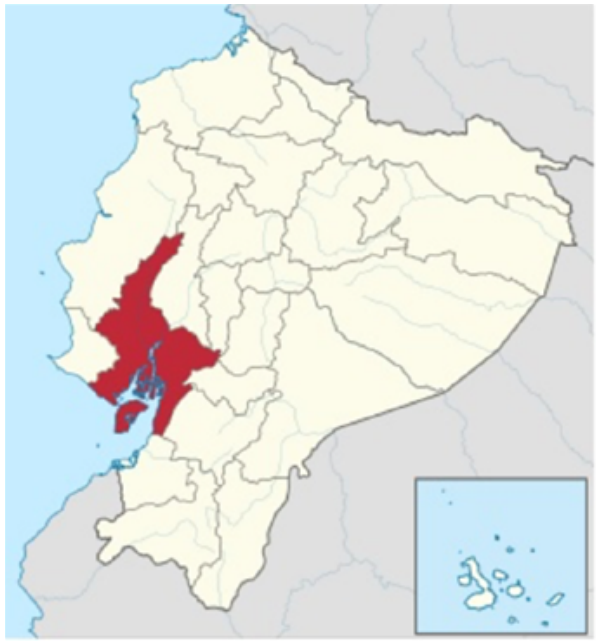

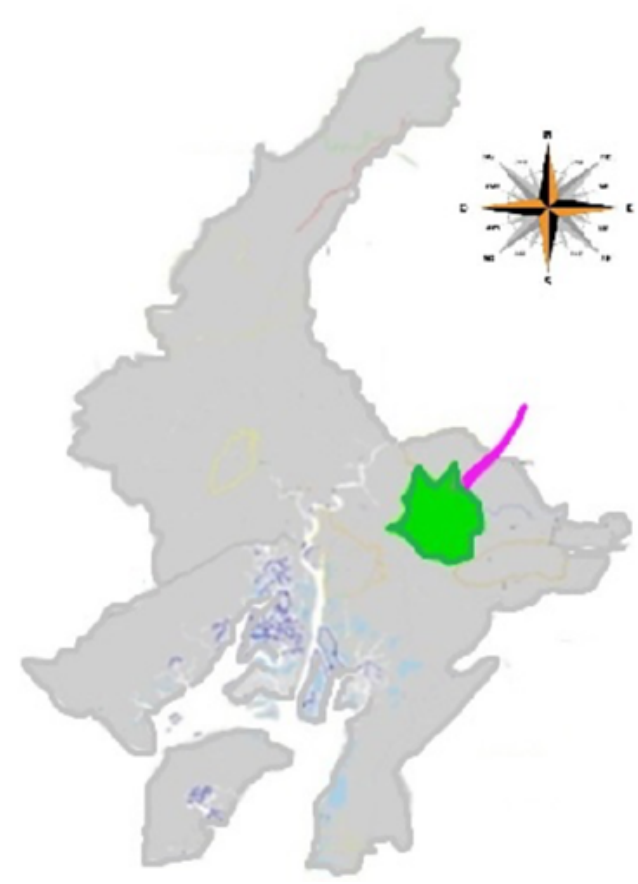

Nota: se agregaron detalles. Fuente: PDOT - Milagro.

de infraestructura está ligada a la capital comercial del país, Guayaquil, ya que por su geolocalización se beneficia del puerto más grande del país, aeropuerto y vías de conexión nacional. Además de la renovada ferrovía -ícono de su historia y desarrollo - , la cual atraviesa la ciudad y la conecta con la zona centro del país. Cuenta también con vías de conexión local, regional, nacional e internacional como la ruta Panamericana. ${ }^{6}$

Históricamente, Milagro siempre estuvo vinculada a la influencia de la ciudad de Guayaquil, primero como ciudad dormitorio en la época de la colonia y, luego como receptora de los flujos migratorios por las actividades de la producción de la caña. En la actualidad, es eje fundamental del servicio público de la zona administrativa. Todas estas cualidades hacen de Milagro un centro urbano de gran importancia dentro de la región y del país, dinamizadora de la economía regional y nacional.
${ }^{6}$ Vía de conexión internacional que atraviesa casi todo el continente americano. 
${ }^{7}$ Empresa Pública Municipal de Movilidad.

territarios 44
Milagro: impactos positivos en la economía y en los servicios de salud y educación

Durante el periodo 2007-2017 cuando se implementaron los planes de desarrollo, el PDOT de Milagro se concentró en el fortalecimiento y desarrollo de sus sectores productivos, así como en la mejora de la calidad de vida de la población, en concordancia con los objetivos nacionales. En estos planes, se evidenciaron resultados con la aplicación de políticas que incentivan el desarrollo de sus sectores productivos, como la política al uso de suelo con fines industriales que atrajo nuevas inversiones a la ciudad.

Respecto a la gestión de las competencias transferidas desde el gobierno central, Milagro hasta el final del 2017 ya las había asumido todas, no obstante, la única competencia que no registró gestión alguna fue la de TTTSV. Pues ya contaban con una empresa de tránsito, ${ }^{7}$ lo que le ha permitido ganar centralidad en la región, reforzando su posición como ciudad intermedia. Cabe señalar que el sector de transporte es uno de los sectores estratégicos básicos para el desarrollo de la economía lo cual resulta un gran aporte al desarrollo de la ciudad.

En lo que respecta a los sectores productivos durante el periodo analizado estos sufrieron alteraciones, siendo el sector de servicios el de mayor dinamismo aportando una contribución mínima de 200 millones de dólares en el 2007 y una contribución máxima de 294 millones de dólares en el 2015 al PIB nacional. El sector agrícola e industrial contribuyó en menor medida, pero con valores próximos entre ellos, como se puede observar en la figura 8 .

En este periodo también se observa que el sector industrial inició un proceso de crecimiento, sobretodo el manufacturero, siendo que, con la implementación del plan de desarrollo la ciudad fue designada como zona de interés para actividades industriales con el beneficio de obtener incentivos fiscales para las nuevas inversiones, alcanzando en el 2016 un valor de inversión de 83,3 millones de dólares.

En cambio, el principal sector de servicios, como se observa en el gráfico 4 , disminuyó significativamente de 106 a 71 millones de dólares entre el 2009 y el 2010, y luego se me mantuvo más o menos estable. Esto se atribuye fundamentalmente a la sustitución de servicios privado por público, como la educación y la salud, así como "la mejora en la calidad de servicio y la repotenciación de las instituciones públicas" (Castro, 2019, p. 140).

Milagro se ha convertido en un centro importante de la red nacional de salud, debido a sus estadísticas concentra un alto porcentaje de asistencia de habitantes y su oferta de servicios es evidente en los resultados. En el periodo analizado, pasó de 200 camas disponibles en el 2007 a 400 camas en el 2016, lo que implica una mayor cobertura de la demanda del 


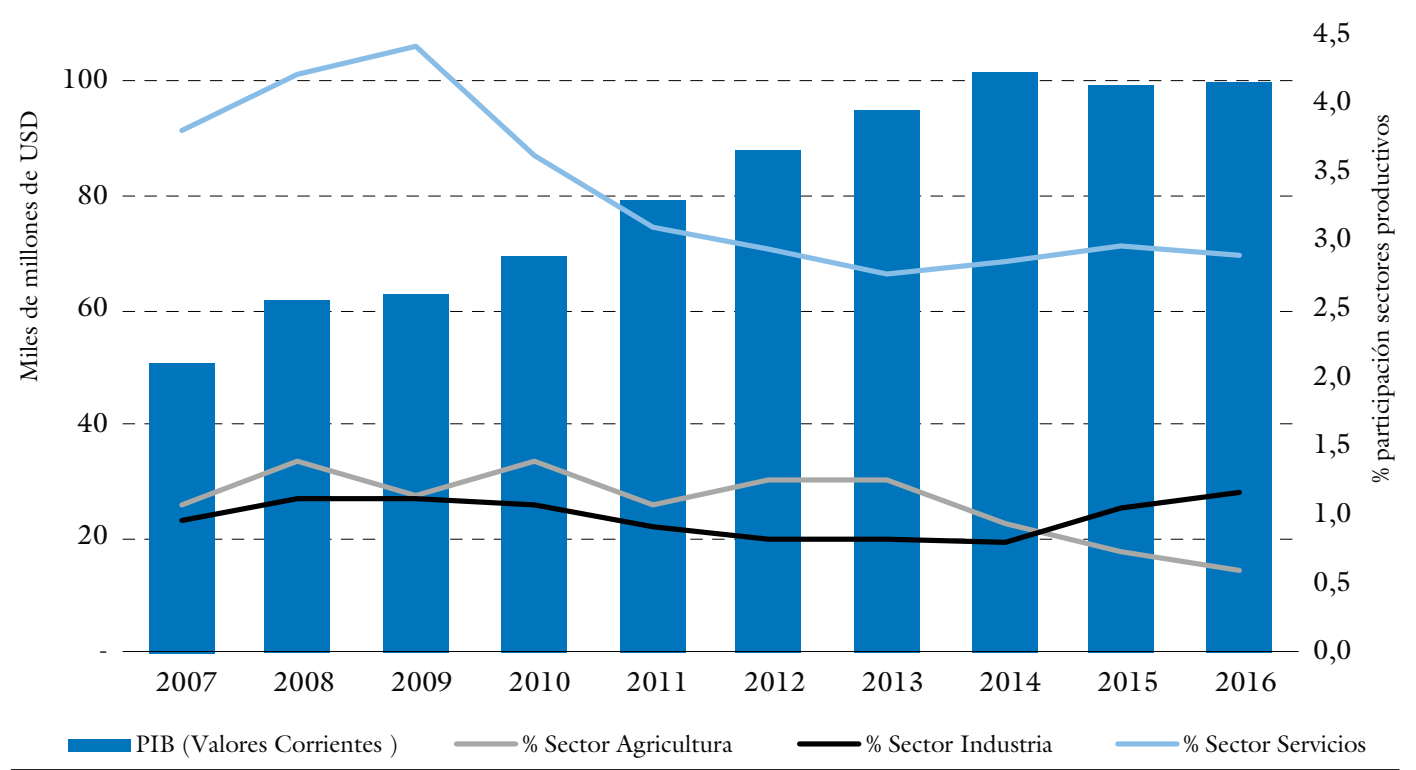

Fuente: elaboración propia a partir de cuentas nacionales del Banco Central del Ecuador.

servicio, acercándose a los estándares internacionales sobre el número de camas por habitante.

El aumento en el número de camas en el sector público fue del $33 \%$ entre el 2007 y el 2014. Sin embargo, el mayor aumento se concentró en el sector privado, de una cifra de 75 camas en el 2007 a 206 en el 2016. Este crecimiento significativo se debe al incremento del número de establecimientos privados, que pasó de 5 a 14 entre el 2007 y el 2016.

En una comparación de la oferta actual y la prevista de los establecimientos de salud en la ciudad de Milagro, se puede determinar que antes de la implementación del proceso de desconcentración, Milagro ya tenía algunos de los establecimientos necesarios para satisfacer la demanda en el cantón y sus alrededores, no obstante, estos, como muchos otros en el resto del país, presentaban precariedad y falta de asistencia por parte de la agencia responsable. Es así como, cumpliendo con la política social en el área de la salud, los centros existentes entraron en un proceso de restructuración para mejorar el servicio ofrecido y su infraestructura.

En lo que corresponde a la inversión en educación durante el periodo 
analizado, en términos nacionales se estimó en un total de 20 mil millones de dólares. Como ejemplo, del 2004 al 2006 el gasto en educación representó el 2,6\% del PIB anual y, para el 2011 esta cifra aumentó a $5,2 \%$ del PIB.

Según datos del Ministerio de Educación, Milagro recibió un total de 691 mil dólares en el 2007 para la reconstrucción de 8 instituciones educativas, en respuesta a la demanda inmediata al comienzo del periodo. Además, el número de escuelas (educación inicial y escolar) se incrementó gradualmente en la ciudad y de acuerdo con la oferta planificada. Así es como en el 2007 el número de escuelas para capacitación inicial y escolar aumentó de 88 a 121 en el 2011.

La prioridad al comienzo de este proceso emprendido fue concentrar los esfuerzos de servicio, proponiendo estrategias emergentes de carácter urgente debido a la precariedad del sistema público, liberando inmediatamente recursos económicos para abastecer la infraestructura necesitada. Entonces bien, tanto en el área de la salud, como el sector educativo, se implementó un proceso de fortalecimiento de las unidades existentes, así como la construcción de nuevas unidades, un proceso que ayudó a mejorar las tasas de pobreza del país.

La característica principal de la década analizada, fue la alta inversión pública realizada para atender el sector social del país, en tanto, las áreas de salud y educación son las de mayor atención en cuanto a la mejora de los índices de cobertura e infraestructura. En el periodo 2007-2016 la inversión pública en educación alcanzó los 24176 MM USD, mientras que, en salud alcanzó 16525 MM USD, una media de 4 y 6 veces más respectivamente de lo registrado en el periodo 2000-2006 (Senplades, 2017). Por lo tanto, el gasto público puede identificarse como el factor más decisivo para aumentar la importancia regional y nacional de la ciudad de Milagro.

\section{Características y cualidades de Milagro como ciudad intermedia}

Entre las características y cualidades que debe tener una ciudad intermediaria, de acuerdo con diferentes aspectos, se destacan las siguientes: ser un centro que sirva bienes y servicios casi especializados tanto para sí misma como para las localidades vecinas; ser un centro de interacción social, económica y cultural; ser centro vinculado a redes de infraestructura que conectan redes locales, regionales y nacionales, e incluso, redes internacionales; ser centro o base administrativa de los niveles de gobierno local y regional, entre otras características locales (Bellet \& Llop, 2004). En tal sentido, Milagro contempla todos estos criterios.

La figura 9 muestra la red urbana de Ecuador y la presencia de ciudades intermedias por criterios de población. Como puede verse, una buena parte de las ciudades se conforma fuera de las principales 
Figura 9. Red urbana en el Ecuador: presencia de las ciudades intermedias

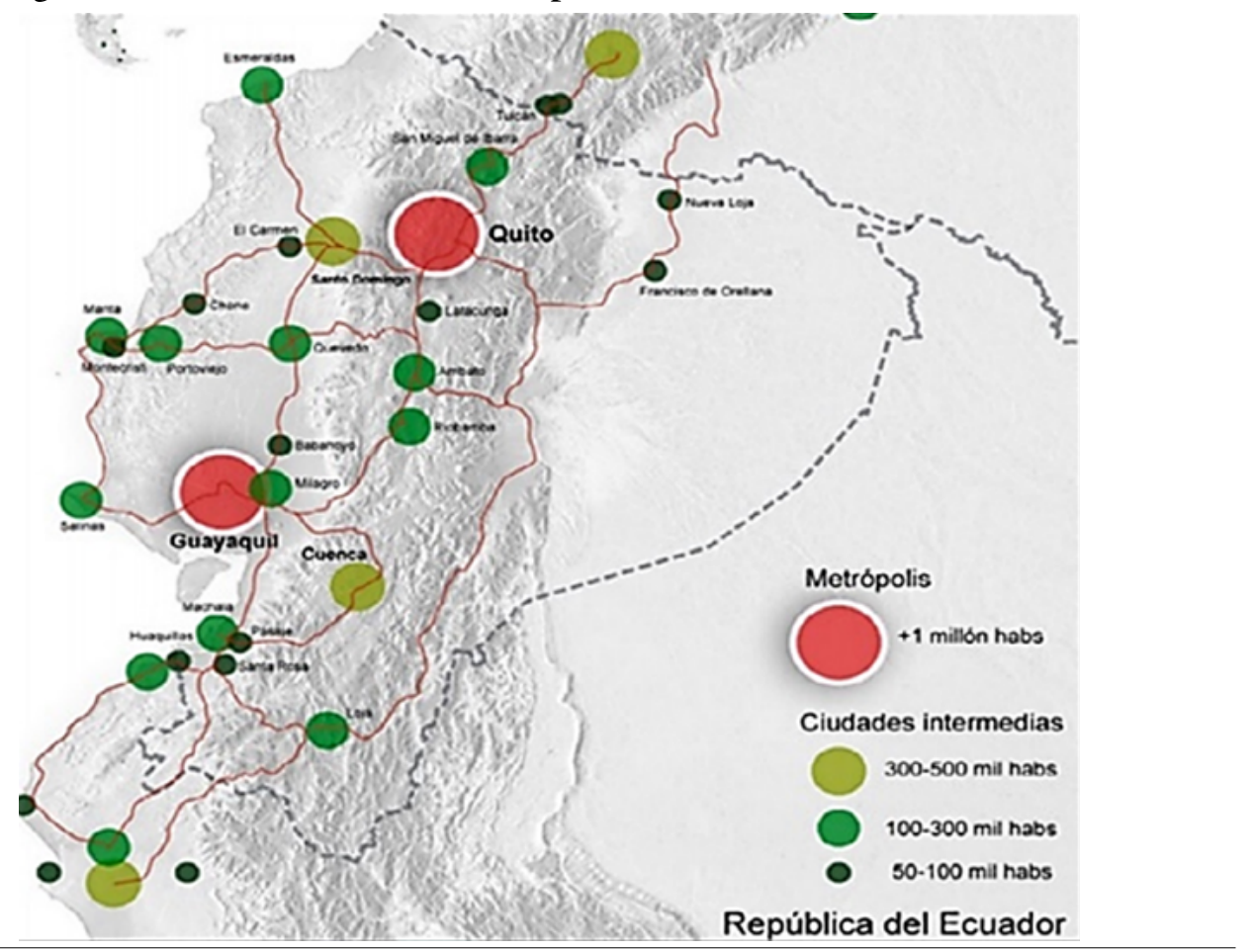

Fuente: elaboración propia a partir de Llop y Vivanco Cruz (2017).

áreas metropolitanas y en diferentes subgrupos de ciudades intermedias: las de 50-100 mil habitantes, las de 100-300 mil habitantes - donde se encuentra la ciudad de Milagro- y los de 300-500 mil habitantes, si se considera los criterios expuestos sobre el tamaño demográfico de las ciudades intermedias (Jordan \& Simioni, 1998).

Desde otra perspectiva, con la reconfiguración del territorio que se implementó durante el periodo analizado, se establecieron jerárquicamente nuevas tipologías en los diferentes asentamientos humanos, así como el rol que ejerce cada uno de ellos dentro del sistema urbano. De esta manera, la ciudad de Milagro como ciudad intermedia se ubica dentro de la tipología de subregionales junto con las ciudades de Santo Domingo, Durán, Daule Chone y Pasaje (Llop \& Vivanco Cruz, 2017).

De igual manera, vale la pena recordar que la ciudad de Milagro no tiene el carácter de una ciudad capital provincial. Esta es una aclaración importante siendo tersitarias 44 
que en Ecuador las ciudades de capitales provinciales - muchas ciudades intermedias dentro de la red urbana-, por su estado, ya poseen y concentran ciertos beneficios estatales, como la localización de los centros administrativos de las instituciones públicas nacionales, lo que contribuye al dinamismo económico local.

Por último, con base en los argumentos de Bellet y Llop (2004) y Corrêa (2017), en la tabla 2 se presenta una correlación de las características que presentan las ciudades intermedias con las características de la ciudad de Milagro. Esto sintetizará la discusión de los cambios en el proceso urbano ecuatoriano. La información cualitativa y cuantitativa presentada en el cuadro se basa en el propio plan de desarrollo, planificación espacial de la ciudad y en las fuentes oficiales de información estadística del país.

Tabla 2. Síntesis de las características de la categoría ciudad intermedia y las cualidades de la ciudad Milagro

\begin{tabular}{|c|c|}
\hline $\begin{array}{l}\text { Ciudad intermedia } \\
\text { (características) }\end{array}$ & Milagro (cualidades) \\
\hline $\begin{array}{l}\text { No existe un tamaño de } \\
\text { población ideal o prede- } \\
\text { finido para las ciudades } \\
\text { intermedias. Un alta tasa } \\
\text { de urbanización es impor- } \\
\text { tante para albergar un } \\
\text { vasto sector de servicios. }\end{array}$ & $\begin{array}{l}\text { - Población total de 166,6 mil habitantes según el censo (INEC, 2010), } \\
\text { con proyección de 174,0 mil habitantes según el INEC para el } 2020 . \\
\text { - Es la tercer área urbana con mayor concentración } \\
\text { de población en la provincia de Guayas. }\end{array}$ \\
\hline $\begin{array}{l}\text { Centro de provisión de } \\
\text { bienes y servicios casi } \\
\text { especializados para la } \\
\text { población de la ciudad y } \\
\text { sus alrededores; centro } \\
\text { de interacción social, } \\
\text { económica y cultural } \\
\text { (función industrial, } \\
\text { función de drenaje } \\
\text { del ingreso cantonal } \\
\text { y función básica de } \\
\text { servicios públicos y } \\
\text { privados esenciales). }\end{array}$ & $\begin{array}{l}\text { - Es la tercer fuerza económica en la provincia, mantiene una cierta } \\
\text { dependencia funcional de la ciudad de Guayaquil, pero ha generado } \\
\text { su propio dinamismo debido a la influencia que tiene en los cantones } \\
\text { circundantes. La producción de bienes y servicios - excepto el } \\
\text { comercio-aporta el } 0,3 \% \text { del PIB nacional. Concentra el } 50,74 \% \text { de la } \\
\text { actividad productiva, el } 51,3 \% \text { de la actividad industrial, el } 60,43 \% \text { de } \\
\text { las actividades comerciales y el } 48,61 \% \text { de las actividades de servicios } \\
\text { en la subregión que comprende los cantones de Alfredo Baquerizo } \\
\text { Moreno (Jujan), Simón Bolívar, Antonio Elizalde (Bucay), Naranjito, } \\
\text { Marcelino Maridueña (San Carlos) y Yaguachi (INEc, 2010). } \\
\text { - Tiene cantones vinculados a las actividades comerciales y de servicio } \\
\text { en Simón Bolívar, Naranjito, Marcelino Maridueña y Yaguachi. } \\
\text { - Tiene la industria azucarera más antigua del país } \\
\text { "Ingenio Valdez", de hecho, su crecimiento como ciudad } \\
\text { está vinculado a esa industria y al ferrocarril. } \\
\text { - Se destaca como la única ciudad, además de Guayaquil, que } \\
\text { tiene centros de educación superior en la provincia de Guayas: la } \\
\text { Universidad Estatal Milagro y la Universidad Agraria de Ecuador. }\end{array}$ \\
\hline
\end{tabular}




\begin{tabular}{|c|c|}
\hline $\begin{array}{l}\text { Ciudad intermedia } \\
\text { (características) }\end{array}$ & Milagro (cualidades) \\
\hline \multirow{6}{*}{$\begin{array}{l}\text { Centro vinculado a redes } \\
\text { de infraestructura que } \\
\text { conectan redes locales, } \\
\text { regionales, nacionales y, } \\
\text { a veces, internacionales. } \\
\text { Es importante tener } \\
\text { una ubicación bien } \\
\text { comunicada por una } \\
\text { red de carreteras, para } \\
\text { facilitar la expansión } \\
\text { de las relaciones con su } \\
\text { entorno inmediato y más } \\
\text { distante. Lo que permite } \\
\text { mantener relaciones } \\
\text { a múltiples escalas } \\
\text { espaciales, con cierto } \\
\text { grado de intensidad. }\end{array}$} & Rutas de conexión: \\
\hline & $\begin{array}{l}\text { - A nivel nacional y regional, es una ciudad que conecta la región del } \\
\text { Litoral con la Sierra Andina. A nivel local, tiene conexión directa } \\
\text { con otras provincias, cantones y parroquias rurales a su alrededor. } \\
\text { A nivel internacional, está conectada a la carretera Panamericana } \\
\text { (E45), carretera que une casi todo el continente americano. }\end{array}$ \\
\hline & Aeropuertos y puertos internacionales: \\
\hline & $\begin{array}{l}\text { - No tiene debido a su geolocalización, está a } 46 \mathrm{~km} \text { de la ciudad de } \\
\text { Guayaquil, ciudad con el segundo aeropuerto más importante del país } \\
\text { y el puerto marítimo. Aproximadamente el } 72 \% \text { de la carga que sale } \\
\text { del puerto es producida por los cantones Quevedo, Vinces y Milagro. }\end{array}$ \\
\hline & Ferrocarril: \\
\hline & $\begin{array}{l}\text { - El ferrocarril atraviesa la ciudad y también conecta las regiones de la } \\
\text { costa y las montañas andinas, desde Durán hasta Quito. Como parte de } \\
\text { la estrategia de turismo del gobierno, el ferrocarril ha sido revitalizado. }\end{array}$ \\
\hline $\begin{array}{l}\text { Centros que albergan } \\
\text { niveles de administración } \\
\text { local y regional (función } \\
\text { de lugar central). }\end{array}$ & $\begin{array}{l}\text { - Concentra diferentes instituciones públicas vinculadas a } \\
\text { la división política y administrativa del ejecutivo. } \\
\text { - Es categorizada como la capital de la zona } 5 \text { de administración. } \\
\text { También concentra las oficinas zonales y distritales de } 18 \\
\text { instituciones públicas de las diferentes funciones del Estado, lo } \\
\text { que genera directa e indirectamente dinamismo en la economía } \\
\text { de la ciudad. (Esto dentro del nuevo modelo de planificación). }\end{array}$ \\
\hline
\end{tabular}

Fuente: elaboración propia a partir de Bellet y Llop (2004), Corrêa (2017), PDOT (2014) e INEC (2010).

\section{Consideraciones finales}

Es notable que el desarrollo urbano ecuatoriano ha estado vinculado a la dinámica de sus padrones de desarrollo económico, sea por sus auges, crisis o por la implementación de políticas públicas. El desarrollo urbano ecuatoriano siempre ha tenido afectación, migraciones masivas y concentración de recursos, que han definido la polarización del sistema urbano existente hasta la actualidad.
Sin embargo, el análisis realizado muestra una mudanza en este paradigma, donde las ciudades intermedias pasan a tener un papel de mayor protagonismo en la red urbana del país, siendo estas las que registran un mayor crecimiento con relación a las grandes ciudades, lo que nos hace suponer que las políticas implementadas pueden generar territorios más equitativos, si se superan los problemas en su modelo económico actual. 
Ahora bien, respecto a la implementación de la política de planificación, ordenamiento territorial y su influencia en el desarrollo de la ciudad de Milagro, se puede concluir que, según los resultados obtenidos a través del análisis de indicadores y la implementación de la política a través de los procesos de descentralización y desconcentración, en particular, la provisión de bienes, servicios y equipos públicos, estos reflejan avances importantes y significativos que refuerza la red urbana del Ecuador y la posición de Milagro como ciudad intermedia en escala regional y nacional.

\section{Referencias}

Achig, L. (1983). El proceso de urbanización en el Ecuador. En El proceso urbano de Quito (Ensayo de interpretación) (pp. 13-15). Centro de investigaciones CIUDAD.

Amorim Filho, O., \& Valente, R. (2001). Evolução e perspectivas do papel das cidades médias no planejamento urbano e regional. En Cidades médias brasileiras (pp. 1-34). IPEA. http://repositorio.ipea.gov. br/bitstream/11058/9872/1/ Evolu\%c3\%a7\%c3\%a3o.pdf

Barrera, A. (2007). Agotamiento de la descentralización y oportunidades de cambio en el Ecuador. En F. Carrión (Ed.), La descentralización en el Ecuador: opciones comparadas (pp. 175-206).
FLACSO. https://doi.org/10.1017/ CBO9781107415324.004

Becker, B. (2005). Dinâmica urbana na Amazônia. En C. Diniz, \& M. Lemos (Orgs.), Economia e Território (pp. 401-428). UFMG.

Bellet, C., \& Llop, J. (2004). Miradas a otros espacios urbanos: las ciudades intermedias. Geo Critica / Scripta Nova. Revista Electrónica de Geografía y Ciencias Sociales, 8(165), 1-28. http://www.ub.edu/geocrit/sn/sn165.htm

Bermúdez, N., Cabrera, H. S., Carrión, A., Del Hierro, S., Echeverría, J., Godard, H., \& Moscoso, R. (2016). La investigación urbana en Ecuador (19902015): cambios y continuidades. En La cuestión urbana en la región andina: miradas sobre la investigación y la formación (pp. 117-173). Centro de Publicaciones, PUCE.

Bocco, A. (1983). Ecuador. Política económica y estilos de desarrollo en la fase de auge petrolero (1972-1978). Instituto de Desarrollo Económico y Social, 22(88), 485-510. https://doi. org/10.2307/3466331

Brandão, C. (2017). Cidades médias como provedoras de bens e serviços públicos e coletivos e como construtoras de cidadania e direitos. En W. R. Silva, \& M. Sposito (Eds.). Perspectivas da urbanização: reestruturação urbana $e$ das cidades. (pp. 99-118). Consequência. 
Brandão, C. (2018). Anotações para uma geoeconomia política transescalar do subdesenvolvimento histórico-geográfico desigual na periferia do capitalismo: lições para América Latina? En C. Brandão, B. J. Pinto, \& L. C. Ribeiro (Eds.), Escalas espaciais, reescalonamentos e estatalidades: lições e desafios para América Latina (pp. 326-360). Observatório das Metrópoles.

Carrión, F. (1985). Alcances de la problemática municipal en las ciudades intermedias ecuatorianas. Centro de Investigaciones CIUDAD, (14), 1-15.

Castro, M. P. (2019). Os efeitos da politica de planejamento no desenvolvimento urbano equatoriano (2007-2016): o caso da cidade de Milagro. Unicamp.

Constitución de la República del Ecuador. (2008). Presidencia de la República del Ecuador. Quito.

Corrêa, R. L. (2006). Estudos sobre a rede urbana. Bertrand Brasil.

Corrêa, R. L. (2007). Construindo o conceito de cidade média. En M. E. B. Sposito (Ed.), Cidades médias: espaços em transição (pp. 23-34). Expressão Popular.

Corrêa, R. L. (2017). Cidades médias e rede urbana. En W. R. Silva, \& M. E. B. Sposito (Org.), Perspectivas da urbanização: reestruturação urbana e das cidades (pp. 29-38). Consequência.

Instituto Geográfico Militar, IMG. (2013). Atlas Geográfico de la República del Ecuador (2da ed.). Senplades.
Instituto Nacional de Estadísticas y Censo, INEC. (2010). Folleto estadisticas censo 2010, Milagro (Vol. 7). Quito.

Instituto Nacional de Estadísticas y Censo, IneC. (2010). Censo de Población y Vivienda. INEC. https://www.ecuadorencifras.gob.ec/base-de-datoscenso-de-poblacion-y-vivienda-2010/

Jordan, R., \& Simioni, D. (1998). Ciudades intermedias de América latina y el caribe: Propuestas para la gestión urbana. CEPAL.

Lavinas, L., \& Ribeiro, L. (1991). Fronteira: terra e capital na modernização do campo e da cidade. En R. Piquet, \& A. C. T. Ribeiro (Org.), Brasil, território da desigualdade: descaminhos da modernização (pp. 69-84). Jorge Zahar.

Llop, J., \& Vivanco Cruz, L. (2017). Ciudades intermedias: características, importancia y oportunidades. En $E l$ derecho a la ciudad en el contexto de la agenda urbana para ciudades intermedias en Ecuador (pp. 47-60). Universidad de Cuenca.

Macedo, F., \& Morais, J. M. (2011). Inserção comercial externa e dinâmica territorial no Brasil: especialização regressiva e desconcentração produtiva regional. Informe Gepec, 15(1), 82-98. https://doi.org/10.48075/ igepec.v15il.5077

Menoscal, J. (2017). El pre litoral ecuatoriano y sus dinámicas de urbanización. Informalidad y construcción social del riesgo en sus ciudades intermedias: 
Quevedo y Milagro (tesis de maestría). FLACSO.

MIDUVI/sHaH. (2015). Informe Nacional del Ecuador para la Tercera Conferencia de las Naciones Unidas Sobre la Vivienda y el Desarrollo Urbano Sostenible Habitát III. Ministerio de Desarrollo Urbano y de Vivienda. https://uploads.habitat3.org/hb3/ National-Report-Ecuador-spanish.pdf Orair, R. O. (2016). Dilemas do financiamento das políticas públicas nos municípios brasileiros: uma visão geral. En M. A. Costa (Ed.), O Estatuto da Cidade e a Habitat III: um balanço de quinze anos da politica urbana no Brasil e a nova agenda urbana (pp. 233-264). IPEA.

PDOT. (2014). Plan de Desarrollo y Ordenamiento Territorial. Municipio de Loja. https://www.loja.gob.ec/files/ image/LOTAIP/podt2014.pdf

PDOT. (2014). Plan de Desarrollo y Ordenamiento Territorial. Milagro. República del Ecuador. http://app.sni. gob.ec/sni-link/sni/PORTAL_SNI/ data_sigad_plus/sigadplusdiagnostic o/0960000730001diagn\%C3\%B3st ico_15-11-2014.pdf

Porto, E. (2003). Desenvolvimento e Território na Babia (N. ${ }^{\circ}$ 61). Superintendência de Estudos Econômicos e Sociais da Bahia.

Porto, L. R. (2016). Urbanização e dinâmica econômica da rede urbana no estado da Babia (1940-2010): o caso de Vitória da Conquista-BA. Unicamp.
Pradilla, E. (1993). Acumulación de capital y estructura territorial en América Latina. Diseño y Sociedad, 3, 4-30. http://www.emiliopradillacobos. com/articulos/PradillaEmilio\%20 $1993 \% 20$ Acumulacion $\% 20 \mathrm{de} \% 20$ capital.pdf

Pradilla, E., \& Márquez, L. (2016). Los territorios latinoamericanos en la mundialización del capital. Territorios, 34(1), 17-34. http://dx.doi. org/10.12804/territ34.2016.01.

Ramírez, C. (2017, 23 de febrero). Mapa Ecuador 2016. https://issuu.com/ carlosalbertoramirezceli/docs/mapa_ecuador_2016

Ramos, E., Da silva, R., \& Garcia, R. (2011). As cidades médias como nódulos de equilíbrio da rede de cidades. Revista Paranaense de Desenvolvimento, 121, 41-63. https://dialnet.unirioja.es/ servlet/articulo? codigo $=3946390$

Santos, M. (2008). Manual de geografía urbana (3ra ed.). EDUSP.

Santos, M. (2010). Ensaios sobre a urbanização latino-americana (2da ed.). EDUSP.

Senplades. (2009). Reforma Democrática del Estado. Rediseño de la función ejecutiva: de las carteras de estado y su modelo de gestión, y de la organización territorial. Secretaría Nacional de Planificación y Desarrollo. https:// www.planificacion.gob.ec/wp-content/uploads/downloads/2012/08/ Reforma-Democr\%c3\%altica-delEstado.pdf 
Senplades. (2017). Informe a la Nación 2007-2017. Secretaría Nacional de Planificación y Desarrollo. http:// www.planificacion.gob.ec/wp-content/uploads/downloads/2017/04/ Informe-a-la-Nacion.pdf

Singer, P. (1973). Campo e cidade no contexto histórico Latino-Americano. Revista Mexicana de Sociologia, 35(2), 301-319. https://doi. org $/ 10.2307 / 3539588$
Sposito, M. E. (2007). Cidades médias: reestruturação das cidades e reestruturação urbana. En M. E. B. Sposito (Org.), Cidades médias: espaços em transição (pp. 233-253). Expressão Popular.

Worldometer (s.f.). Map of Ecuador Political. https://www.worldometers.info/ 